\title{
Physician Assistant Students' Perceptions of the Fitness Industry and Lifestyle Medicine
}

\section{ALYSSA ABREU1, SARAH-ANN KEYES², MARK D. FARIES 3}

${ }^{1}$ Human Performance Laboratory; Kinesiology; Stephen F. Austin State University; Nacogdoches, TX

${ }^{3}$ Baylor College of Medicine, Houston, TX

${ }^{3}$ College of Medicine; Texas A\&M University Extension Service; College Station, TX

Category: Masters

Advisor/Mentor: Faries, MarkD. (Mark.Faries@ag.tamu.edu)

\section{ABSTRACT}

With nearly two-thirds of all chronic disease having a lifestyle cause, there is spurred interest in curricular changes for Physician Assistants (PA) and other medical providers to learn Lifestyle Medicine (LM) - the therapeutic use of lifestyle changes to prevent, treat and reverse disease. A key competency in LM practice involves an interdisciplinary approach, including aid from fitness professionals. Yet, perceptions of the fitness industry might hinder such a relationship.

PURPOSE: To assess PA students' knowledge of LM and perceptions of the fitness industry, to guide curriculum implementation efforts. METHODS: An online survey was advertised to all PA students at Baylor College of Medicine. Students' competence in assessing and prescribing physical activity and diet, knowledge of LM, current curriculum time spent on LM, and desire to learn more about LM were assessed. Students were also asked to share their attitude of both health clubs and personal trainers, alongside referral perceptions. RESULTS: 76 (84\%) of students $\left(25.57 \pm 4.86\right.$ years; $\left.22.77 \pm 4.20 \mathrm{~kg} / \mathrm{m}^{2}\right)$ completed the survey, self-reporting moderate competence (range: 1-6) in conducting a physical exam to approve an exercise program (4.22 \pm $1.22)$, determining caloric and nutritional needs $(3.80 \pm 1.34)$, and designing an exercise prescription $(3.57 \pm 1.35)$. However, only $18 \%, 6 \%$, and $6 \%$ self-rated full competence in each, respectively. $31 \%$ of students had heard of the discipline of LM, with $43 \%$ self-reporting inadequate or poor knowledge. $0 \%$ felt they spent enough time on LM in their program, and 78\% rated their time spent on LM was either poor or inadequate. Yet, $100 \%$ wanted to learn more. Perceptions of health clubs and personal trainers were positive ( $8.16 \pm 1.68$; range: $1-10)$, with them being appropriate exercise venues for patients $(7.78 \pm 1.76)$. However, only $6 \%-16 \%$ believed that health clubs and personal trainers were fully qualified, effective, smart, and concerned about patient health. CONCLUSIONS: Despite the role of lifestyle on chronic 
disease, PA students had limited competence and knowledge in LM, but held a unanimous desire for more in their educational training. Perceptions of the fitness industry were generally positive; yet educational efforts might be needed to encourage a team-approach to chronic disease care.

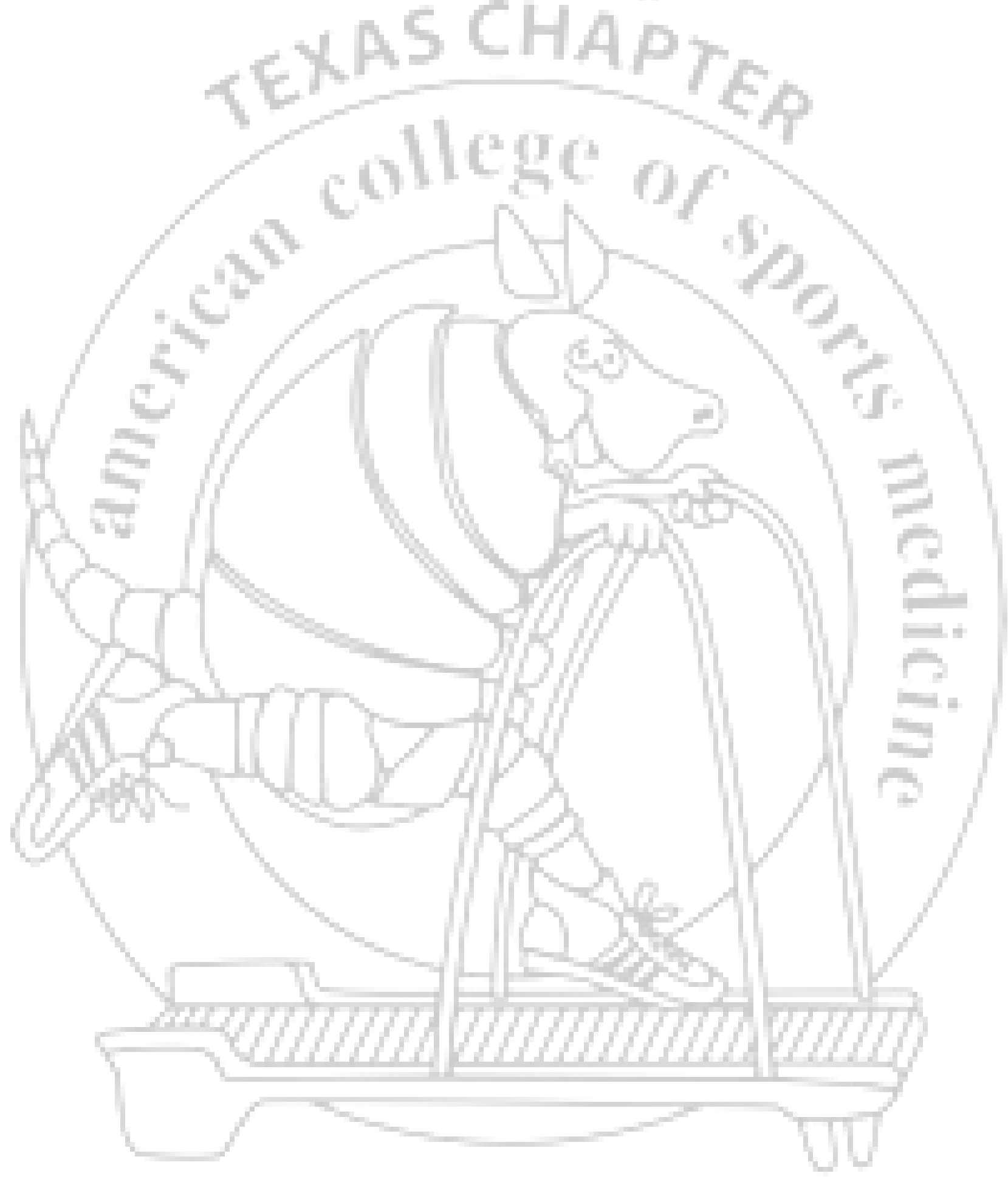

